\title{
Risk Factors Associated with Helicobacter Pylori Infection in Children with Gastrointestinal Symptoms

\author{
Million Polfan ${ }^{\mathrm{a}, *}$, Supriatmo ${ }^{\mathrm{a}}$, Winra Pratita ${ }^{\mathrm{a}}$, Gontar Alamsyah Siregar ${ }^{\mathrm{b}}$, \\ Gema Nazri Yanni ${ }^{a}$, Pertin Sianturia \\ *millionpolfan@gmail.com \\ a Department of Child Health, Faculty of Medicine, Universitas Sumatera Utara, Jalan Dr Mansur No 5, Medan, 20155, Indonesia \\ ${ }^{\mathrm{b}}$ Department of Internal Medicine, Faculty of Medicine, Universitas Sumatera Utara, Jalan Dr Mansur No 5, Medan, 20155, Indonesia
}

\begin{abstract}
Background: The main cause of peptic ulcer disease in children is H. pylori, which has also been proven as a carcinogen in human. With an estimated high prevalence and its chronic nature, it is important to determine the risk factors for $H$. pylori infection. Studies in adults have shown association of $H$. pylori infection with several risk factors, but research in children is still scarce.

Objective: To determine the risk factors associated with $H$. pylori infection in children with gastrointestinal symptoms.

Methods: This was a case-control study in children with gastrointestinal symptoms treated at H. Adam Malik General Hospital in Medan from September 2019 - June 2020. Diagnosis of H. pylori infection was made if one of the diagnostic tests was positive. Data was then collected from parents with a questionnaire guidance and was analysed to determine the association between the risk factors with the incidence of $H$. pylori infection.

Result: A total of 68 children ( 34 cases and 34 controls) met the criteria as sample. Age range of subjects was between 2-17 years with a median of 12.5 years. Routine hand washing (before eating, after defecation, and when hands were dirty) decreases the risk of $H$. pylori infection ( $\mathrm{P}=0.040$; OR 0.2 ; 95\% CI 0.4-1.04). History of bottle feeding beyond 2 years old increases the risk of $H$. pylori infection $(\mathrm{P}=0.041$; OR 3.59; 95\% CI 1.01-12.73).

Conclusion: Routine hand washing and a history of bottle feeding beyond 2 years old are associated with the incidence of $H$. pylori infection.
\end{abstract}

Published by IJRP.ORG. Selection and/or peer-review under responsibility of International Journal of Research Publications (IJRP.ORG)

Keywords: Helicobacter pylori; risk factors; children; gastrointestinal

\section{Introduction}

Gastritis and peptic ulcers were initially associated with psychological factors. This theory was then shifted to stomach acid as the main cause of gastritis and ulcers. In 1983, Warren and Marshall proved that 
Helicobacter pylori (H. pylori) can cause gastritis and peptic ulcers (Marshall and Warren, 1984). By 1994, National Institutes of Health Consensus Development Conference (NIHCDC) concluded that the leading cause of gastric ulcers in the pediatric population was H. pylori. The International Agency for Research on Cancer Working Group (IARCWG) of the World Health Organization (WHO), also in the same year, classified H. pylori as a group of carcinogens in humans (Crowley and Hussey, 2016).

Helicobacter pylori is slow-growing, gram-negative microaerophilic bacteria that colonize the gastric mucosa, with an estimated 65\% of children in developing countries infected (Rowland et al., 2006). The prevalence of $H$. pylori infection, in patients with gastrointestinal symptoms who underwent endoscopic examinations in several hospitals in Indonesia between 2003 and 2004, was 10.2\% (Syam, 2016). In other study, the prevalence rate differs among ethnic groups living in the same geographic area. It was then hypothesized that differences in socioeconomic status, personal hygiene, and number of family members as the probable cause. This was supported by data which showed the seroprevalence of $H$. pylori infection in Estonia in 1991 for children aged $11-15$ years was $42.2 \%$, decreasing to $28.2 \%$ in 2002 as the country became increasingly prosperous (Daugule et al., 2016).

Helicobacter pylori infection commonly occurs in early childhood. The manifestations of $\mathrm{H}$. pylori infection in children include gastrointestinal and extraintestinal manifestations. Gastrointestinal manifestations include gastritis, gastric ulcers, gastroesophageal reflux, and gastric carcinoma. Extraintestinal manifestations include iron deficiency anemia, short stature, allergic and autoimmune diseases (Crowley and Hussey, 2016). Considering the morbidity attributable to $H$. pylori infection, analysis of the risk factors for $H$. pylori infection is warranted. Identification of risk factors will help in understanding its transmission and, furthermore, can reduce the incidence of chronic infections which can progress to recurrent abdominal pain and malignancy.

\section{Methods}

\subsection{Subjects and Methods}

This was an analytical observational study with a case-control design, carried out between September 2019 and July 2020. All patients were children aged 2 to 18 years with at least two complaints of gastrointestinal symptoms (recurring abdominal pain, flatulence, nausea, excessive belching and loss of appetite) within 2 months before the examination. All patients were tested with either one of $H$. pylori stool antigen (HPSA), urea breath test (UBT), or endoscopy with Campylobacter-like organism (CLO) test, also known as rapid urease test, to confirm the diagnosis of $\mathrm{H}$. pylori infection. Patients with history of consumption of proton pump inhibitor (PPI), antibiotics, Histamine H-2 receptor antagonists (H2RA), bismuth, or sucralfate within 14 days prior to the diagnostic test for $\mathrm{H}$. pylori, or patients with clinical symptoms and signs of acute abdomen who required emergency care were excluded.

The sampling method was non-randomized consecutive sampling in which all samples were recruited sequentially until the required sample size was met. Risk factors was recorded using questionnaire. Nutritional status was assessed by anthropometric examination using body weight over height according to Waterlow criteria (WHO 2006 for children aged 2-5 and CDC 2000 for children aged 5-18 years old) and divided into undernourished, normal, and overweight criteria (Waterlow, 1972). Parents's socioeconomic level was based on the regional minimum wage in Sumatera Utara Province (Badan Pusat Statistik, 2019). Ethnic of the subjects was based on the father's. Either active or passive smoker was included as a criteria for 

when the child or caregiver (for children who cannot eat or wash themselves) almost always wash their hands before eating, after defecating, and when their hands are dirty.

All research subjects were asked for consent from parents after being given an explanation in advance about the purpose of this study. The study was conducted at H. Adam Malik General Hospital.

\subsection{Research Ethics}

This study was approved by the Health Research Ethical Committee of the Faculty of Medicine, Universitas Sumatera Utara/ H Adam Malik General Hospital no 939/tgl/kepk FK USU-RSUP HAM/2019.

\subsection{Statistical Analysis}

The collected data were processed and analyzed using computer software SPSS version 23.0. Univariate analysis was used to describe the characteristics of the sample. Categorical data are presented in terms of frequency and percentage. Numerical data are presented in medians (ranges) because the data are not normally distributed. Bivariate analysis assesses the relationship between categorical variables using chisquare test. For bivariate that did not meet the chi-square rule, an alternative Fisher's exact test was used for data with $2 \times 2$ tables, whereas for data with $2 \times k$ tables, the variables were grouped into two groups and reanalyzed using similar procedure. Multivariate analysis was then performed using logistic regression tests on variables that had a p value $<0.25$ and were statistically significant with the incidence of $H$. pylori from the bivariate test analysis, to determine the risk factors that influence the incidence of $H$. pylori infection in children in this study. Statistical analyzes were performed with $95 \%$ confidence intervals and a $\mathrm{p}$ value $<0.05$ was considered statistically significant.

\section{Results}

\subsection{Characteristics of Research Subjects}

The subjects involved in this study were 68 children (34 sample and 34 control) that met the inclusion and exclusion criteria. The mean age of the subjects was 12.5 years with an age range of 2-17 years. The mean body weight was $38 \mathrm{~kg}$ with a weight range from 9 to $85 \mathrm{~kg}$ and a mean height value was $143 \mathrm{~cm}$ with a range of 84 to $170 \mathrm{~cm}$. Total of $9(13.2 \%)$ children was undernourished and $27(39.7 \%)$ children was overweight. Complete characteristic data are presented in Table 1.

Table 1. Characteristics of research subjects

\begin{tabular}{lc}
\hline Characteristics & $\mathbf{n}=\mathbf{6 8}$ \\
\hline $\boldsymbol{H}$. pylori diagnostic tests, $\mathbf{n}(\boldsymbol{\%})$ & $8(11.8)$ \\
HPSA & $10(14.7)$ \\
UBT & $50(73.5)$ \\
Endoscopy (CLO) & $12.5(2-17)$ \\
Age (years), median (min-max) & $22(32.4)$ \\
2-9, n (\%) & $46(67.6)$ \\
10-18, n (\%) & \\
Gender, n (\%) & $26(38.2)$ \\
Boy & $42(61.8)$ \\
Girl & $38(9-85)$ \\
Weight, median (min-max) & $143(84-170)$ \\
Height, median (min-max) & \\
\hline
\end{tabular}




\begin{tabular}{|c|c|}
\hline \multicolumn{2}{|l|}{ Nutritional status, n (\%) } \\
\hline Undernourished & $9(13.2)$ \\
\hline Normal & $32(47.1)$ \\
\hline Overweight & $27(39.7)$ \\
\hline \multicolumn{2}{|l|}{ Ethnic, n $(\%)$} \\
\hline Batak & $29(42.6)$ \\
\hline Minang & $4(5.9)$ \\
\hline Aceh & $7(10.3)$ \\
\hline Java & $13(19.1)$ \\
\hline Malay & $10(14.7)$ \\
\hline Chinese & $4(5.9)$ \\
\hline India & $1(1.5)$ \\
\hline \multicolumn{2}{|l|}{ Father's education, n (\%) } \\
\hline High school & $10(14.7)$ \\
\hline University & $58(85.3)$ \\
\hline \multicolumn{2}{|l|}{ Mother's education, $\mathbf{n}(\%)$} \\
\hline High school & $6(8.8)$ \\
\hline University & $62(91.2)$ \\
\hline \multicolumn{2}{|l|}{ Father's occupation, $\mathbf{n}(\%)$} \\
\hline Farmer & $2(2.9)$ \\
\hline Civil servant & $7(10.3)$ \\
\hline Employee & $37(54.4)$ \\
\hline Entrepreneur & $19(27.9)$ \\
\hline Army / police & $3(4.4)$ \\
\hline \multicolumn{2}{|l|}{ Mother's occupation, n (\%) } \\
\hline Farmer & $3(4.4)$ \\
\hline Civil servant & $7(10.3)$ \\
\hline Employee & $29(42.6)$ \\
\hline Entrepreneur & $18(26.5)$ \\
\hline Housewife & $11(16.2)$ \\
\hline \multicolumn{2}{|l|}{ Socio-economic, n (\%) } \\
\hline$<2 \mathrm{x}$ regional minimum wage & $5(7.4)$ \\
\hline$>2 \mathrm{x}$ regional minimum wage & $63(92.6)$ \\
\hline \multicolumn{2}{|c|}{ Family history of $H$. pylori infection, n (\%) } \\
\hline No & $23(33.8)$ \\
\hline Yes & $45(66.2)$ \\
\hline \multicolumn{2}{|l|}{ Cigarette smoke exposure, n (\%) } \\
\hline No & $28(41.2)$ \\
\hline Yes & $40(58.8)$ \\
\hline \multicolumn{2}{|l|}{ Hand washing habit, n (\%) } \\
\hline Rarely & $10(14.7)$ \\
\hline Routine & $58(85.3)$ \\
\hline \multicolumn{2}{|l|}{ Bottle feeding, $n(\%)$} \\
\hline Stop before 2 years old & $15(22.1)$ \\
\hline Beyond 2 years old & $53(77.9)$ \\
\hline
\end{tabular}


3.2. Risk Factors and Incidence of H. pylori Infection

Hand washing habit significantly reduced the incidence of $H$. pylori infection with an odds ratio of 0.2 (95\% CI $=0.40-1.04)$. History of bottle feeding beyond 2 years old significantly increased the incidence of $H$. pylori infection by 3.59 times $(95 \% \mathrm{CI}=1.01-12.73)$.

Age, gender, nutritional status, father's ethnicity, father's and mother's education, father's and mother's occupation, socioeconomic level of parents, family history of $H$. pylori infection, and exposure to cigarette smoke did not have a statistically significant effect on the incidence of $H$. pylori infection (p value> 0.05). The details of these factors can be seen in Table 2.

Table 2. Relationship between risk factors and the incidence of $H$. pylori infection

\begin{tabular}{|c|c|c|c|c|c|c|c|c|c|}
\hline \multirow[t]{2}{*}{ Risk Factors } & & \multicolumn{2}{|c|}{ (-) H. pylori } & \multicolumn{2}{|c|}{ (+) H. pylori } & \multirow[t]{2}{*}{ OR } & \multicolumn{2}{|c|}{$95 \% \mathrm{CI}$} & \multirow[t]{2}{*}{$\mathrm{p}$ value } \\
\hline & & $\mathrm{N}$ & $\%$ & $\mathrm{~N}$ & $\%$ & & Min & Max & \\
\hline \multirow[t]{2}{*}{ Age } & $2-9$ yrs & 10 & 45.5 & 12 & 54.5 & 0.76 & 0.28 & 2.12 & $0.604 *$ \\
\hline & $10-18$ yrs & 24 & 52.2 & 22 & 47.8 & 1.00 & & & \\
\hline \multirow[t]{2}{*}{ Gender } & Girl & 19 & 45.2 & 23 & 54.8 & 0.61 & 0.23 & 1.63 & $0.318 *$ \\
\hline & Boy & 15 & 57.7 & 11 & 42.3 & 1.00 & & & \\
\hline \multirow{4}{*}{$\begin{array}{l}\text { Nutritional } \\
\text { status }\end{array}$} & Undernourished & 3 & 33.3 & 6 & 66.7 & 0.45 & 0.10 & 1.98 & $0.476 * *$ \\
\hline & $\begin{array}{l}\text { Not } \\
\text { undernourished }\end{array}$ & 31 & 52.5 & 28 & 47.5 & 1.00 & & & \\
\hline & Overweight & 13 & 48.1 & 14 & 51.9 & & & & \\
\hline & Normal & 18 & 56.3 & 14 & 43.8 & & & & \\
\hline \multirow[t]{8}{*}{ Ethnic } & Batak & 14 & 48.3 & 15 & 51.7 & 0.89 & 0.34 & 2.32 & $0.806 *$ \\
\hline & Not Batak & 20 & 51.3 & 19 & 48.7 & 1.00 & & & \\
\hline & Minang & 1 & 25.0 & 3 & 75.0 & & & & \\
\hline & Aceh & 4 & 57.1 & 3 & 42.9 & & & & \\
\hline & Java & 9 & 69.2 & 4 & 30.8 & & & & \\
\hline & Malay & 3 & 30.0 & 7 & 70.0 & & & & \\
\hline & Chinese & 3 & 75.0 & 1 & 25.0 & & & & \\
\hline & India & 0 & 0.0 & 1 & 100.0 & & & & \\
\hline \multirow{2}{*}{$\begin{array}{l}\text { Father's } \\
\text { education }\end{array}$} & High school & 6 & 60.0 & 4 & 40.0 & 1.61 & 0.41 & 6.30 & $0.493 *$ \\
\hline & University & 28 & 48.3 & 30 & 51.7 & 1.00 & & & \\
\hline \multirow{2}{*}{$\begin{array}{l}\text { Mother's } \\
\text { education }\end{array}$} & High school & 3 & 50.0 & 3 & 50.0 & 1.00 & 0.19 & 5.34 & $1,000 * *$ \\
\hline & University & 31 & 50.0 & 31 & 50.0 & 1.00 & & & \\
\hline \multirow{6}{*}{$\begin{array}{l}\text { Father's } \\
\text { occupation }\end{array}$} & Employee & 19 & 51.4 & 18 & 48.6 & 1.13 & 0.43 & 2.93 & $0.808 *$ \\
\hline & Not employee & 15 & 48.4 & 16 & 51.6 & 1.00 & & & \\
\hline & Civil servant & 4 & 57.1 & 3 & 42.9 & & & & \\
\hline & Farmer & 1 & 50.0 & 1 & 50.0 & & & & \\
\hline & Entrepreneur & 8 & 42.1 & 11 & 57.9 & & & & \\
\hline & Army/police & 2 & 66.7 & 1 & 33.3 & & & & \\
\hline \multirow{6}{*}{$\begin{array}{l}\text { Mother's } \\
\text { occupation }\end{array}$} & Employees & 15 & 51.7 & 14 & 48.3 & 1.13 & 0.43 & 2.95 & $0.806 *$ \\
\hline & Not employees & 19 & 48.7 & 20 & 51.3 & 1.00 & & & \\
\hline & Civil servants & 3 & 42.9 & 4 & 57.1 & & & & \\
\hline & Farmer & 1 & 33.3 & 2 & 66.7 & & & & \\
\hline & Entrepreneur & 9 & 50.0 & 9 & 50.0 & & & & \\
\hline & Housewife & 6 & 54.5 & 5 & 45.5 & & & & \\
\hline \multirow{2}{*}{$\begin{array}{l}\text { Parents's } \\
\text { socio- } \\
\text { economic }\end{array}$} & $<2 \mathrm{x}$ min wage & 3 & 60.0 & 2 & 40.0 & 1.55 & 0.24 & 9.91 & $1,000 * *$ \\
\hline & $>2 x$ min wage & 31 & 49.2 & 32 & 50.8 & 1.00 & & & \\
\hline \multirow{2}{*}{$\begin{array}{c}\text { Family history } \\
\text { of } H \text {. pylori }\end{array}$} & No & 12 & 52.2 & 11 & 47.8 & 1.14 & 0.42 & 3.12 & $0.798 *$ \\
\hline & Yes & 22 & 48.9 & 23 & 51.1 & 1.00 & & & \\
\hline
\end{tabular}




\begin{tabular}{llcccccccc}
\hline $\begin{array}{l}\text { infection } \\
\text { Cigarette }\end{array}$ & No & 16 & 57.1 & 12 & 42.9 & 1.63 & 0.62 & 4.32 & $0.324 *$ \\
$\quad$ smoke & Yes & 18 & 45.0 & 22 & 55.0 & 1.00 & & & \\
$\quad$ exposure & & & & & & & & & \\
Hand washing & Rarely & 2 & 20.0 & 8 & 80.0 & 0.20 & 0.04 & 1.04 & $0.040 *$ \\
$\quad$ habit & Routine & 32 & 55.2 & 26 & 44.8 & 1.00 & & & \\
Bottle feeding & $<$ 2 years & 11 & 73.3 & 4 & 26.7 & 3.59 & 1.01 & 12.73 & $0.041 *$ \\
& $>$ 2 years & 23 & 43.4 & 30 & 56.6 & 1.00 & & & \\
\hline
\end{tabular}

* chi-square test

** Fisher's exact test

\subsection{Multivariate Analysis Results}

The variables that had a $\mathrm{p}$ value $<0.25$ and statistically significant for the incidence of $H$. pylori infection (hand washing habit and bottle feeding until more than 2 years old) were analysed by multivariate analysis using backward LR logistic regression test. The results are presented in Table 3.

Table 3. Logistic regression test results

\begin{tabular}{lccccc}
\hline & OR & \multicolumn{2}{c}{$95 \%$ CI } & B & P value \\
\cline { 3 - 4 } & & Min & Max & & \\
\hline Hand washing habit & 0.05 & 0.00 & 0.55 & $-3,036$ & 0.015 \\
Bottle feeding > 2years old & 12.86 & 1.55 & 106.81 & 2,554 & 0.018 \\
\hline
\end{tabular}

\section{Discussion}

A total of 68 children with gastrointestinal symptoms, who were treated at H. Adam Malik General Hospital in Medan, were divided into two groups. The first was with H. pylori (+) infection and the second, control group, was without $H$. pylori infection. Each group consist of 34 children. The diagnosis of $H$. pylori infection was based on the results of one of the HPSA examinations (8 subjects), UBT (10 subjects), endoscopy and CLO (50 subjects). All of these diagnostic examination have a high sensitivity and sensitivity toward H. pylori infection (Koletzko S et al., 2011; Yanez et al., 2000; Glupczynski, 1998; Kato et al., 2003).

\subsection{Age}

The largest age group that participated in this study was 10-18 years old, consisted of $46(67.6 \%)$ children. The incidence of $H$. pylori infection was almost equal in the 2-9 years old age group (54.5\%) and in the $10-18$ years old age group (47.8\%). Hence, we can assume that $H$. pylori infection has occurred in young children which is in line with the result of a study in Ireland which showed that $H$. pylori infection has occurred in children between 2 to 4 years old (Rowland et al., 2006). A study in Latvia even found that the incidence $H$. pylori infection is highest in children under 5 years old (Daugule et al., 2016). Meanwhile, the results of studies in Uganda and China found that the incidence of $H$. pylori infection increases with increasing age of the child (Aitila et al., 2019; Ding et al., 2015).

\subsection{Gender, Nutritional Status, and Parent's Education Level}

A study in Taiwan, from a cross-sectional study, found no association between $H$. pylori infection and growth failure measured in body weight, height, and body mass index (Chi H et al., 2009). However, a 

with low socioeconomic levels, presumably through mechanisms involving growth-related molecules (ghrelin) (Ozen et al., 2011).

From the results of our study, there were no significant differences between the incidence of $H$. pylori infection with gender, nutritional status, and parent's education level. This may be due to the disequilibrium of the sample, of which only 9 children $(13 \%)$ who were malnourished. Majority of the subject's parent, $58(85 \%)$ with father and $62(91 \%)$ with mother, went to university, The rest have parents who had finished high school. Thus, conclusion from this can be bias and cannot be compared with studies in Vietnam and China that show the education level of parents (especially mothers) as a protective factor against the incidence of H. pylori infection to her child (Nguyen at al., 2017; Ding et al., 2015).

\subsection{Parent's Occupation and Socioeconomic Status}

Helicobacter pylori is transmitted via the faecal-oral route. Hence, socioeconomic is thought to play a role in $H$. pylori infection because it is related to sanitation (Aitila et al., 2019; Nguyen at al., 2017; Darnindro et al., 2015). The occupation of the parents of the subjects in this study were mostly employees (54.5\% father and $42.6 \%$ mother). But from a socioeconomic perspective, the total income of both parents of $92 \%$ of the subjects was more than 2x the UMR (province minimum wage), which we categorized as middle and upper economic groups. From this study, there was no relationship between parent's occupation and socioeconomic status with the incidence of $H$. pylori infection.

\subsection{Family History of $H$. pylori Infection}

Of the total study subjects, 45 children $(66.2 \%)$ had a family history of $H$. pylori infection. One possible explanation is that if there are family members who are infected, there will be an awareness to check other family members for the same disease. In this study, there was no statistically significant relationship between family history and the incidence of $H$. pylori infection in children. This is different from most other studies that have found an increased risk of $H$. pylori infection when there is a family history of infection, such as in studies in Vietnam, Ireland, China (Nguyen at al., 2017; Farrel et al., 2005; Ding et al., 2015).

\subsection{Exposure to cigarette smoke}

Secondhand smoke exposure is a debatable possible risk factor for $H$. pylori infection. Smoking itself is a major risk factor for peptic ulcer disease by stimulating gastric acid secretion and weakening the gastric mucosal barrier, thereby triggering gastric atrophy which in itself can also lead to malignancy. From a study in India and Brazil in adult subjects, it was found that smoking increases the risk of $H$. pylori infection (Mhaskar et al., 2013; Basilio et al., 2018). However, our study did not find statistically significant relationship between cigarette smoke exposure and the incidence of $H$. pylori infection in children.

\subsection{Hand Washing Behavior}

Transmission of $H$. pylori is via faecal-oral route, so the incidence of $H$. pylori infection is deemed to be associated with sanitation status and had been demonstrated in several studies, including a study in the adult population in Jakarta which found an association between environmental sanitation and $H$. pylori infection (Darnindro et al., 2015). The Vietnamese study also specifically found that not washing hands regularly after defecating was a risk factor for the incidence of $H$. pylori infection (Nguyen et al., 2017). From the multivariate regression results of a study, hand hygiene was also found to be a protective factor for the incidence of $H$. pylori infection (Ding et al., 2015).

The majority $(85.3 \%)$ of the sample in this study routinely washed their hands with soap before 
eating, after defecating, and when their hands were dirty. The behavior of washing hands itself is very subjective, so that in this study, we tried to reduce bias by explaining clearly in detail to parents (during the process of filling out the questionnaire) the parameters that had been determined, which was the habit of washing hands before eating, after defecating, and if hands were dirty. It should be emphasized that due to the fairly wide age range in the subjects of this study, we took note to include child's caregiver habit for children who could not take care of themselves. Hand washing behavior $(\mathrm{p}=0.040)$ and history of bottle feeding beyond 2 years old $(\mathrm{p}=0.041)$ were two risk factors that were found to be significantly associated with the incidence of $H$. pylori infection in this study.

\subsection{History of Bottle Feeding}

History of bottle feeding beyond 2 years old were stated as a risk factor from the results of a study in Ireland (Rowland et al., 2006). This is based on the principle of transmission of $H$. pylori via the faecal-oral route. H. pylori (in the form of coccoid) can be detected by the PCR in samples in contaminated mineral water, so it is possible that $\mathrm{H}$. pylori can also be found in milk bottles that are not properly washed (Bahrami et al., 2013).

\subsection{Research Limitations and Strengths}

This study has several limitations including:

- Has a wide age range so that some research parameters can be bias. For example, the hand washing behavior is different between children aged 2 years and adolescent. The accuracy of history of bottle feeding beyond 2 years old is also doubtful in older children.

- Subjects are not normally distributed. The majority of the subjects are middle and upper socioeconomic groups with a minimum parental education was high school and the majority even university graduated.

The advantages of this research are:

- This is a pioneering study on the risk factors for $H$. pylori infection in children in Indonesia. Although similar studies have been published based on research results in other countries, until the time of this publication, in Indonesia there had only been research on adults.

- The diagnosis of H. pylori infection used one of the HPSA, UBT, and endoscopy (CLO) methods which have high sensitivity and specificity values (Koletzko S et al., 2011; Yanez et al., 2000; Glupczynski, 1998; Kato et al., 2003).

\section{Conclusion}

Hand washing behavior (before eating, after defecating, and if hands are dirty) and a history of bottle feeding beyond 2 years old are significantly associated with the incidence of $H$. pylori infection in children with gastrointestinal complaints. There are no association between age, sex, nutritional status, ethnicity, education and occupation of parents, socioeconomic status, family history of $H$. pylori infection, or exposure to cigarette smoke with the incidence of $H$. pylori infection in children.

Further research is needed with a sample population that is normally distributed from a socioeconomic perspective and a more specific age division. 


\section{Acknowledgements}

The author give a token of appreciation to all clinical staff in Pediatric Department, Faculty of Medicine, Universitas Sumatera Utara especially in Gastroenterology division, who had contributed to the completion of this study.

\section{References}

Aitila P, Mutyaba M, Okeny S, Kasule MN, Kasule R, Sedyabane F, et al. Prevalence and risk factors of Helicobacter pylori infection among children aged 1 to 15 years at Holly Innocents Children's Hospital, Mbarara, South Western Uganda. J Trop Med. 2019 ; 1-6.

Badan Pusat Statistik [Internet]. 2019 [cited 5 Mei 2019]. Available from: https://www.bps.go.id/linkTableDinamis/view/id/917

Bahrami AR, Rahimi E, Safaei HG. Detection of Helicobacter pylori in city water, dental unit's water, and bottled mineral water in Isfahan, Iran. Sci World J. 2013; 280510:1-5.

Basilio ILD, Catao MFC, Carvalho JDS, Neto FPF, Ferreira LC, Jeronimo SMB. Risk factors of Helicobacter pylori in an urban community in Northeast Brazil and the relationship between the infection and gastric diseases. Rev Soc Bras Med Trop. 2018; 51(2):183-9.

Chi H, Bair MJ, Wu MS, Chiu NC, Hsiao YC, Chang KY. Prevalence of Helicobacter pylori infection in high-school students on Lanyu island, Taiwan: risk factor analysis and effect on growth. J Formos Med Assoc. 2009; 108(12): 929-36.

Crowley E, Hussey S. Helicobacter pylori in Childhood. In: Wyllie R, Hyams JS, Kay M, eds. Pediatric Gastrointestinal and Liver Disease. $5^{\text {th }}$ ed. Philadelphia: Elsevier; 2016. p. 309-27.

Darnindro N, Syam AF, Fauzi A, Rumende CM. Seroprevalence and socio-demographic factors of Helicobacter pylori infection in patients with dyspepsia in Kalibaru primary health care north Jakarta. Acta Med Indones. 2015; 47:297-303.

Daugule I, Karklina D, Rudzite D, Remberga S, Rumba-Rozenfelde I. Prevalence of H pylori infection among preschool children in Latvia. Scand J Public Health. 2016; 44:418-22.

Ding Z, Zhao S, Gong S, Li Z, Mao M, Xu X, et al. Prevalence and risk factors of Helicobacter pylori infection in asymptomatic Chinese children: a prospective, cross-sectional population-based study. Aliment Pharmacol Ther. 2015; 42:1019-26.

Farrell S, Doherty GM, Milliken I, Shield MD, McCallion WA. Risk factors for Helicobacter pylori infection in children. An examination of the role played by intrafamilial bed sharing. Pediatr Infect Dis. 2005; 24(2):149-52.

Glupczynski Y. Microbiological and serological diagnostic tests for Helicobacter pylori: an overview. Acta Gastroenterol Belg. 1998; 61:321-6.

Kato S, Ozawa K, Okuda M. Accuracy of the stool antigen test for the diagnosis of childhood Helicobacter pylori infection: a multicenter Japanese study. Am J Gastroenterol. 2003; 98:296-300.

Koletzko S, Jones NL, Goodman KJ. Evidence-based guidelines from ESPGHAN and NASPGHAN for Helicobacter pylori infection in children. J Pediatr Gastroenterol Nutr. 2011; 53:230-43.

Marshall BJ, Warren JR. Unidentified curved bacilli in the stomach of patients with gastritis and peptic ulceration. Lancet. 1984; 1:13115.

Mhaskar RS, Ricardo I, Azliyati A, Laxminarayan R, Amol B, Santosh W, Boo K. Assessment of risk factors oh Helicobacter pylori infection and peptic ulcer disease. J Glob Infect Dis. 2013; 5(2):60-7.

Nguyen TVH, Phan TTB, Nguyen VB, Hoang TTH, Le TLA, Nguyen TTM, et al. Prevalence and risk factors of Helicobacter pylori infection in Muong children in Vietnam. Ann Clin Lab Res. 2017; 5(1):1-9.

Ozen A, Furman A, Berber M. The effect of Helicobacter pylori and economic status on growth parameters and leptin, ghrelin, and insulin-like growth factor (IGF)-I concentrations in children. Helicobacter. 2011; 16:55-65.

Rowland M, Daly L, Vaughan M. Age-specific incidence of Helicobacter pylori. Gastroenterology. 2006; 130:65-72.

Syam AF. Current situation of Helicobacter pylori infection in Indonesia. Med J Indones. 2016; 25:1-4.

Waterlow JC. Classification and definition of protein-calorie malnutrition. Br Med J. 1972;3:566-9.

Yanez P, la Garza AM, Perez-Perez G. Comparison of invasive and noninvasive methods for the diagnosis and evaluation of eradication of Helicobacter pylori infection in children. Arch Med Res. 2000; 31:415-21. 